\title{
Estudo da razão comprimento/diâmetro de tubulação de óleo de girassol e de etanol para o escalonamento da produção de biodiesel em microrreatores
}

\section{Fernando Liedmann*, Mariana G. M. Lopes, Osvaldir P. Taranto e Harrson S. Santana}

\section{Resumo}

O presente trabalho busca encontrar uma razão comprimento/diâmetro para os tubos de conexão dos distribuidores de vazão e microrreatores de forma a igualar as perdas de pressão do etanol e do óleo, reagentes que escoam separadamente nesses tubos. Isso proporciona uma grande melhora para a reação no microrreator.

\section{Palavras-chave: \\ Microfluídica, Biodiesel, Microplanta.}

\section{Introdução}

Ao misturar óleo de girassol com etanol e um catalisador, como o hidróxido de sódio, há a produção de biodiesel pela reação de transesterificação. É possível realizá-la com microrreatores. Estes melhoram a área de contato e o rendimento da reação. De forma a aumentar a produção, utiliza-se o escalonamento, ou seja, colocar vários microrreatores em paralelo, obtendo uma microplanta. Antes dos reagentes serem misturados nos microdispositivos, eles passam por um distribuidor de vazão que uniformiza o fluxo em cada microrreator. No escoamento dos reagentes nos tubos que ligam os distribuidores aos microdispositivos, a grande diferença de viscosidade entre o óleo e o etanol pode afetar muito o processo, pois, sob as mesmas condições, a perda de pressão do óleo será muito maior que a perda de pressão do etanol. Então, o óleo escoará lentamente até a entrada do microrreator, podendo até mesmo obstruir o escoamento do etanol. Utilizando a equação da energia e o coeficiente de Darcy para escoamento laminar, é possível obter uma expressão para o cálculo da perda de pressão nos tubos $-\Delta P=128 L_{n} \mu Q / \pi D^{4}$, em que $\Delta P$ é a perda de pressão em tubulações, $L_{n}$ é o comprimento da tubulação, $\mu$ é a viscosidade dinâmica do fluido, $Q$ é a vazão e $D$ é o diâmetro da tubulação.

Assim, esse trabalho avaliou a queda de pressão em função de diferentes alturas e vazões para uma microplanta química composta por quatro microrreatores utilizados na síntese de biodiesel com o objetivo de igualar a perda de pressão de óleo de girassol e etanol para os microrreatores utilizados.

\section{Resultados e Discussão}

Para o início do estudo foram estabelecidos os seguintes critérios, baseado em estudos anteriores: Comprimento do tubo de etanol $\left(\right.$ Lett, $\left._{1}=6 \mathrm{~cm}\right)$, altura até 0 distribuidor de vazão de etanol $\left(H_{\mathrm{et}, 1}=4,3 \mathrm{~cm}\right)$, o que resulta em uma razão $\mathrm{L} / \mathrm{H}$ de 1,4 . A razão de vazão óleo/etanol (Qól/Qet) é 1,8 e os tubos utilizados foram tubos Masterflex com diâmetro de 6,4 mm para o óleo e de 3,1 $\mathrm{mm}$ para o etanol. Assim, a única variável desconhecida é o comprimento do tubo de óleo (Lól,1) que pode ser encontrado ao aplicar a ferramenta Solver do Excel. Após obtê-lo, a altura até o distribuidor de vazão de óleo $\left(\mathrm{Hob}_{\text {ó, }}\right)$ é encontrada. A diferença de altura entre cada microrreator $(\Delta \mathrm{H})$ é igual a $2,4 \mathrm{~cm}$. Então, pelas seguintes Equações $H_{\text {at } n}=H_{\text {at } 1}+(n-1) \Delta H$ e $L_{n}=1,4 \Delta H$, obtém-se as alturas dos outros microrreatores em relação ao distribuidor de vazão de etanol e o comprimento do tubo de etanol, respectivamente. Com a mesma lógica utilizada para o microrreator 1, obtém-se o comprimento do tubo de óleo para os outros microrreatores. Todos os dados obtidos estão na Tabela 1, a qual mostra que para as vazões consideradas é possível obter um conjunto de configurações $(\mathrm{H}$ e $\mathrm{L}$ ) em que as quedas de pressões são iguais para ambos os reagentes. A Figura 1 mostra a perda de carga em função da vazão para os quatros microrreatores, em que é possível observar o mesmo comportamento em diferentes vazões.

Tabela 1. Valores obtidos para o comprimento do tubo de óleo (Lól) e para a diferença de altura do microrreator ao distribuidor de óleo (Hól) ao igualar a perda de pressão. Q em mL.min ${ }^{-1}, \mathrm{H}$ e L em cm e $\triangle \mathrm{P}$ em Pa.

\begin{tabular}{c|ccc|ccc|c} 
Microrreator & $\mathbf{Q}_{\text {et }}$ & $\mathbf{H}_{\text {et }}$ & $\mathbf{L}_{\text {et }}$ & $\mathbf{Q}_{\text {ol }}$ & $\mathbf{H}_{\text {ól }}$ & $\mathbf{L}_{\text {ól }}$ & $\boldsymbol{\Delta} \mathbf{P}$ \\
\hline 1 & & 4,30 & 6,00 & & 0,94 & 1,32 & 15,8 \\
2 & & 6,70 & 9,35 & & 1,47 & 2,05 & 24,6 \\
3 & 30,0 & 9,10 & 12,7 & & 2,00 & 2,79 & 33,4 \\
4 & & 11,5 & 16,0 & & 2,52 & 3,52 & 42,3 \\
\hline
\end{tabular}

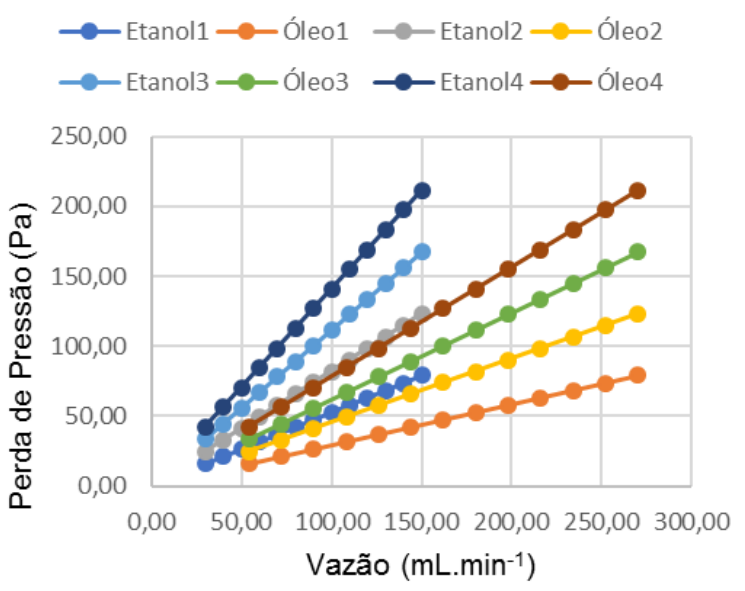

Figura 1. Influência da vazão na perda de pressão nas entradas de etanol e óleo dos quatro microrreatores.

\section{Conclusões e Agradecimentos}

Como o óleo é mais viscoso que o etanol, a sua perda de pressão é muito maior para um mesmo comprimento e diâmetro de tubo. Então, analisando o cálculo da perda de pressão, observou-se um comprimento do tubo de óleo menor e o diâmetro maior, de modo a diminuir essa perda de pressão e igualar à perda do etanol. Em trabalhos futuros, experimentos serão realizados para confirmar os resultados obtidos aqui. Os autores agradecem ao CNPq, CAPES e FAPESP - Processo 2016/20842-4. 